\title{
XXII. Remarks on Dr. Mills's Researches on Thermometry.-No. II
}

\section{T.E. Thorpe Ph.D. F.R.S. \& A.W. Rücker M.A.}

To cite this article: T.E. Thorpe Ph.D. F.R.S. \& A.W. Rücker M.A. (1881) XXII. Remarks on Dr. Mills's Researches on Thermometry.-No. II, Philosophical Magazine Series 5, 12:74, 184-189, DOI: $10.1080 / 14786448108627090$

To link to this article: http://dx.doi.org/10.1080/14786448108627090

曲 Published online: 17 May 2010.

Submit your article to this journal $[\pi$

ЏII Article views: 2

Q View related articles $\square$ 
work; but I confine myself here to what has been actually done. It is hoped that the difficulties are now for the most part overcome, and that the attainment of further results is not far distant.

XXII. Remarks on Dr. Mills's Researches on Thermometry.No. II. $B y$ T. E. THORPE, Ph.D.. F.R.S., and A. W. RÜCKER, M.A.*

TN a criticism on Dr. Mills's Researches on Thermometry, 1 published in the July number of the Philosophical Magazine, we stated that we believed that he had committed an error" which " upsets all the inferences drawn by him from his formulæ" relating to the movement of the zero of a mercurial thermometer with changes of temperature. In his reply, Dr. Mills informs us that he has "so far failed to follow" the section of our paper in which this remark occurs, "that he is unable to discuss it." It is evident that the question at issue between us cannot thus be left unsettled. We purpose therefore briefly to notice some of the points on which Dr. Mills has replied to us, and to attempt to make still clearer those which he disregarded as unintelligible.

Exposure Correction.-Dr. Mills is wrong in thinking that we questioned the accuracy of his statement that the "correction-factors" for his thermometers were the same at certain temperatures named by him. What we stated (Phil. Mag. July 1881, p. 12) was, that his method of presenting his results "tends to exaggerate the importance of the variation of the corrections." To this we adhere-and the more strongly, inasmuch as $D_{r}$. Mills's immediately succeeding remarks afford an example of the confusion introduced into the discussion of the subject by his habit of dealing, not with the quantities which it was his object to determine (e.g. corrections, positions of the ice-point), but with subsidiary quantities (correction-factors, total remaining ascents), by which they are only indirectly measured.

We stated that, in our opinion, Dr. Mills's experiments prove that the "exposure corrections [expressed by $y=$ $(\alpha+\beta \mathrm{N})(\mathrm{T}-t) \mathrm{N}]$ below $100^{\circ} \mathrm{C}$. are in the case of three out of four similar thermometers practically identical ;" and we supported our view by an example calculated for $100^{\circ} \mathrm{C}$. Dr. Mills retorts that our inference is clearly wrong, because at lower temperatures the differences of the correction-factors (i. e. of $\alpha+\beta \mathrm{N}$ ) are greater than at $100^{\circ}$. This we fully

* Communicated by the Authors. 
admit; but, on the other hand, at the lower temperatures both $\mathrm{N}$ and $\mathrm{T}-t$ must be less than at $100^{\circ}$. They, too, are factors of the correction; and if their variations are taken into account, our statements that the example worked out by us was favourable to Dr. Mills's views, and that the corrections for three of the thermometers were practically identical below $100^{\circ}$, are strictly correct. Let us investigate this point a little more fully.

The corrections may be considered as practically identical if, in the case of any thermometer, we may substitute for the correction peculiar to it the mean of the corrections obtained from all the thermometers.

For the thermometers referred to by us $(2,3$, and 6$)$ the expression for the mean correction is

$$
y=(\cdot 00013591+\cdot 000000051152 \mathrm{~N}) \mathrm{N}(\mathrm{T}-t) .
$$

Subtracting this from the correction for thermometer 2 , we get the difference

$$
\delta=(\cdot 00000557-\cdot 000000013272 \mathrm{~N}) \mathrm{N}(\mathrm{T}-t) .
$$

If $\mathrm{N}$ varies, the maximum value of this expression occurs when $N=210$ seale-divisions (each of which on Dr. Mills's thermometers was a millimetre in length, and corresponded approximately to $0^{\circ} \cdot 25$ C.). Making the same liberal assumption as in our last communication, that $T-t=100$, we obtain, if we write $\Delta$ for the maximum difference from the mean correction, $\Delta=0.06$ division.

For thermometer 3 we get (neglecting signs) $\Delta=0.07$ dir. when $\mathrm{N}=335$ div. In the case of thermometer 6 the two curves intersect below 400 div. The correction-difference is a maximum and $=0.01$ div. when $\mathrm{N}=111$ div., is zero when $\mathrm{N}=$ 222 div., and is $=0.05$ div. when $\mathrm{N}=400$ div. The largest of the above values of $\Delta$ is a little above the error of reading; and we may for a moment digress to say that we do not think there is any difference of opinion between ourselves and Dr. Mills as to the value of this quantity. We said it is "impossible to read with certainty to less than a tenth" of a millimetre. Dr. Mills can read "fairly" (i.e. not with certainty) to a twentieth. We have frequently had occasion to read the same thermometer independently. We invariably agree to $0^{\mathrm{c}} \cdot 01$ ( $i$. e. on our thermometers to a tenth of a millimetre), thus showing that the error of reading is \pm 0.05 millim.

To return, however, to our argument. If, instead of taking the three thermometers with respect to which our statement was made, we take all four, we find for thermometer 4 (that previously excluded) $\Delta=0.23$ div. when $\mathrm{N}=400$ div. For 
thermometer $2, \Delta=0.11$ when $N=273$. In the case of thermometer $3, \Delta=0 \cdot 01$ when $\mathrm{N}=156$; $\delta$ vanishes when $\mathrm{N}=312$, and is 0.01 . when $N=400$. Finally, in the case of thermometer 6 , the largest value of $\delta$ is $0 \cdot 13$, which occurs when $\mathrm{N}=400$.

Of these quantities, the value of $\Delta$ for thermometer 4 is considerably in excess of the error of reading. It is not in this case, however, a question of the error of reading only. An experiment conducted with an exposed scale is in that respect conducted under unfavourable circumstances; and the other errors thus introduced are far more important. This can readily be shown from Dr. Mills's own paper.

He says (Trans. Roy. Soc. Edinb. 1880, p. 570) that there appeared to be in the experiments some source of variation which I could not detect." Thus the value of the correctionfactor varied between 0.000113 and 0.000164 in the first of the three series of observations of which details are given, between 0.000136 and 0.000165 in the second, and between 0.000140 and 0.000166 in the third. On the other hand, the mean correction-factor for all the thermometers, and that for thermometer 4 , both calculated for $\mathrm{N}=400$ div. (for which in this case $\delta$ has its largest value), are 0.000155 and 0.000149 respectively. The difference between these numbers is evidently well within the above limits of error, and is in fact exactly equal to the probable error of a single determination as calculated by Prof. Mills.

On the whole, then, we are disposed to extend rather than to withdraw our previous statement, and to say that Dr. Mills's experiments go far to prove that the exposure correction below $100^{\circ} \mathrm{C}$. is practically the same for all similar thermometers. Nor is this a matter of slight importance. Dr. Mills's investigation of the exposure correction of one of his thermometers involved 2160 readings. Had his conclusion that "each thermometer is proved to have its own independent equation for exposure correction " been correct in the sense that the differences were important, every observer working with exposed thermometers, who wished to attain the highest possible degree of accuracy, would in like manner have been compelled to make hundreds or even thousands of observations on each instrument. He would have had either to repeat Dr. Mills's research, or to undertake some not less difficult and laborious comparison with a standard for which the correction was known. Dr. Mills cannot, therefore, be surprised if, before consenting to accept such a yoke, we closely examine the grounds upon which it is imposed. We believe that he has rendered a greater service to his fellow-workers than he him- 
self supposed-that he has removed, instead of imposing a burden. If he had bestowed some of the attention he has devoted to the variations of the correction-factor on those of the correction itself, he would not have left it for us to point out that the latter are negligible. As it is, the error introduced by taking the mean correction for similar thermometers instead of that for the thermometer actually enployed, never exceeded the probable error of an observation; and the chances appear to be three to one that, with a given thermometer, under the most unfavourable circumstances of exposure and temperaturedifference, it cannot exceed half that amount.

Passing on to the next point noticed by Dr. Mills, he is mistaken in thinking that, by a confusion between the correction-factor and the correction, we have attributed to him the statement that it is possible "for the correction for a thermometer with an exposed column 166 divisions long to be equal to that of another when no part of the column is exposed." As a matter of fact his paper does, owing to a misprint, implicitly contain this statement; and the passage to which he refers is a reductio ad absurdum to show that a misprint must exist.

Zero-movements.-On the question of nomenclature we have little to add. We agree that words are sometimes used in other than their usual significations in "physical writings." In such cases, however, good reasons for departure from ordinary usage are generally forthcoming, and the word is defined on its first introduction in its new sense.

We now come to the point which Dr. Mills fails to understand; and in our further remarks upon it we will confine ourselves to the case of Henrici's thermometer.

Unfortunately, we cannot discuss the question "mathematical formula apart," as Dr. Mills seems to wish. The whole point turns upon the deductions drawn by Dr. Mills from his mathematical formulæ, which cannot, therefore, be dispensed with.

The "total remaining ascent" of Henrici's thermometer is expressed by Dr. Mills by the equation

$$
y=2 \cdot 100(\cdot 931)^{x}-\cdot 099(1 \cdot 360)^{x} . \quad . \quad .
$$

We concluded that the position of zero $(Z)$ is connected with $y$ by the relation

$$
\mathrm{Z}=-2+y, \cdot \cdot \cdot \cdot \cdot \cdot
$$

a conclusion supported by the fact that this equation holds for all the five values of $y$ and of the "zero observed," given in Table VII. But if this is so, since $y$ has no maximum or minimum value, $Z$ cannot have one either. The motion of the 


\section{Remarks on Dr. Mills's Researches on Thermometry.}

zero is thus given by the formula as unchangeable in direction. It is not reversed when $y=0$; and the evidence, if of any value outside the range of the experiments, is directly opposed to the theory of the three movements of the zero of a thermometer.

To make the matter clearer, we reproduce Dr. Mills's table with three additional rows, which are separated from the rest by a line, and with some additions to the headings of the columns.

\begin{tabular}{|c|c|c|c|}
\hline$x$. & $\begin{array}{l}\text { Zero observed. } \\
\text { Z. }\end{array}$ & $\begin{aligned} & y \\
&=2+z .\end{aligned}$ & $\begin{array}{l}y \text { calculated from } \\
\text { formula (1). }\end{array}$ \\
\hline $\begin{array}{l}0 \\
1 \\
3 \\
4 \\
5\end{array}$ & $\begin{array}{r}0.00 \\
-0.10 \\
-0.25 \\
-0.40 \\
-0.60\end{array}$ & $\begin{array}{l}2 \cdot 00 \\
1 \cdot 90 \\
1 \cdot 75 \\
1 \cdot 60 \\
1 \cdot 40\end{array}$ & $\begin{array}{l}1 \cdot \overline{92} \\
1 \cdot 73 \\
1 \cdot 61 \\
1.45\end{array}$ \\
\hline $\begin{array}{l}9 \\
9 \cdot 35 \\
10\end{array}$ & $\begin{array}{l}-1.81 \\
-2.00 \\
-2.41\end{array}$ & $\begin{array}{l}\ldots \ldots . . \\
\cdots \cdots \cdot \\
\cdots \cdots \cdot \\
\cdots . . .\end{array}$ & $\begin{array}{r}0 \cdot 19 \\
0.00 \\
-0.41\end{array}$ \\
\hline
\end{tabular}

The last three numbers in the second column are calculated from the formula $y=2+Z$. The Table shows that the zero continues to descend though $y$ becomes negative. The same considerations may, mutatis mutandis, be applied to Dr. Mills's own thermometers. The only one for which there is a critical value is thermometer 3 ; and that corresponds to a negative value of $x$. There is, we believe, no flaw in this argument, and it certainly is not abstruse ; but, in view of the ambiguity of the term "total remaining ascent," we assumed, when writing before, that Dr. Mills might be able to explain the difficulty. We therefore reminded him of certain canons for the use of empirical formulæ, which, if his conclusions were not invalidated by the previous objection, were applicable to the case under discussion. His admission that these were not novel does not explain his disregard of them.

In concluding his reply to our paper, Dr. Mills seeks to reduce our criticisms to "an obvious misprint, a slip in arithmetic, a question of mere nomenclature, and the like."

The misprint was only incidentally noticed in a discussion as to whether his method of exposition did not exaggerate the importance of the variations of the exposure correction-a discussion which, as we have seen, involves the whole scope and meaning of this portion of bis work.

The slip in arithmetic occurred in the formula which, though Dr. Mills has never employed it himself, is the first to which any one desirous to make use of his results would turn. 
The question of nomenclature was avowedly introduced to show that Dr. Mills had involved the subject in some obscurity, and that therefore, if we had misunderstood him in the more important matter to follow, we must ask for indulgence.

The remainder of our paper was occupied with a discussion as to the accuracy of his deductions from his equations. $\mathrm{He}$ himself says (loc. cit. p. 574) it is important to illustrate these; and he can therefore hardly stigmatize as triviality the question as to whether the illustrations are correct.

XXIII. Inverse Problem of Criticoids. By Sir JAMEs CockLE, M.A., F.R.S., F.R.A.S., F.C.P.S., Mem. Lond. Math. Soc., Corr. Mem. Lit. and Phil. Soc. Manchester, Hon. Mem. Roy. Soc. Nevo South Wales, late.Pres. Queensland Phil. Soc.*

1. TN a "Supplement on Binomial Biordinals," recently 1 printed in the "Proceedings of the London Mathematical Society' (vol. xiii. pp. 63-72), I have, in certain cases, linked a binomial of the second with one of the third order wherein the symbolical factors of both numerator and denominator are in arithmetical progression. The theory of criticoids expounded in these pages sheds a light upon this result and gives a foreshadowing of others.

2. All binomial terordinals may be included in

$$
\frac{d^{2} y}{d x^{3}}+\frac{3}{x} \frac{a+e x^{n}}{1+x^{n}} \frac{d^{2} y}{d x^{2}}+\frac{3}{x^{2}} \frac{f+g x^{n}}{1+x^{n}} \frac{d y}{d x}+\frac{1}{x^{3}} \frac{h+k x^{n}}{1+x^{n}} y=0 \text {. }
$$

3. For brevity I put

$$
\begin{aligned}
& 1+x^{n}, \quad a+e x^{n}=\mathrm{X}, \quad a_{1}, \\
& f+g x^{n}, \quad l+k x^{n}=a_{2}, \quad a_{3},
\end{aligned}
$$

and denote differentiations by accents, thus, and by a multiplication, changing the terordinal into

$$
\mathrm{X} x^{3} y^{\prime \prime \prime}+3 a_{1} x^{2} y^{\prime \prime}+3 a_{2} x y^{\prime}+a_{3} y=0 .
$$

4. Take the criticoid, viz. deprive the equation of its second term by assuming a new dependent variable $z,=y x^{n} \mathrm{X}\left(\frac{e-a}{n}\right)$, and divide by the leading coefficient. We thus get

$$
z^{\prime \prime \prime}+3 s z^{\prime}+t z^{\prime}=0,
$$

wherein $\delta$ and $t$ are defined by

$$
\begin{aligned}
& \mathrm{X}^{2} x^{2} s=\mathrm{L}+\mathrm{M} x^{n}+\mathrm{N} x^{2 n} \\
& \mathrm{X}^{3} x^{3} t=\mathrm{P}+\mathrm{Q} x^{n}+\mathrm{R} x^{2 n}+\mathrm{S} x^{3 n} . \\
& \text { * Communicated by the Author. }
\end{aligned}
$$

Phil. Mag. S. 5. Vol. 12. No. 74. Sept. 1881. 